\title{
DAMPAK SOSIAL EKONOMI PEMBANGUNAN JALAN DAN EXIT TOL DI WILAYAH KOTA PEKALONGAN
}

\author{
Siti Nurhayati ${ }^{1}$, Paminto Agung Christianto ${ }^{2}$, Zahro ${ }^{3}$, Choliq Sabana ${ }^{4}$ \\ 1,3,4 Universitas Pekalongan, \\ ${ }^{2}$ STMIK Widya Pratama Pekalongan \\ 1,2,3,4 Dewan Riset Daerah Kota Pekalongan
}

\begin{abstract}
Abstrak
Pekalongan Municipality Government hopes that the toll exit will be able to help ease access to the Setono Wholesale Market, so that batik traders from outside the municipality who want to shop to Pekalongan faster and easier. However, a growing phenomenon in batik traders in Setono Wholesale Market said that the construction of the toll road caused their sales turnover to decline quite a lot. Meanwhile many people who previously had a livelihood in agriculture had to give up land affected by toll road construction. Even though they get sufficient compensation, to switch professions to find a new job is not easy considering that most farmers do not have other skills. On the other hand, many people have benefited from the existence of toll roads, including the opportunity to find work during the toll road construction season, as well as those who can work in the rest area. Seeing the positive and negative perceptions of the community towards the construction of roads and toll exits, an in-depth and detailed study will be carried out on the socioeconomic impacts on the construction of toll roads and exits that pass through Pekalongan Municipality.

Research data will be collected through documentation and questionnaire distribution methods, which will then be processed using descriptive methods. In general, the community stated that the construction of toll roads and exits facilitates transportation access to health services and education services, but does not affect the ease of access to government services, and is able to dismiss the issue that the existence of toll roads and exits causes traders' income to fall, but in fact $55.56 \%$ of respondents stated an increase in income and increased the number of kiosks or shops to sell.
\end{abstract}

Keywords: Impact, Toll exit, Pekalongan

\section{PENDAHULUAN}

Proses pembangunan yang secara fisik dibutuhkan oleh suatu Negara adalah pembangunan infrastruktur. Keberadaan infrastruktur memiliki peran yang sangat penting dalam mewujudkan interaksi sosial dan kelangsungan sistem perekonomian. Semakin baik keadaan infrastruktur, semakin baik pula pengaruhnya terhadap interaksi sosial dan keadaan ekonomi suatu wilayah serta akan memacu kemajuan dan perkembangan suatu wilayah. Hal tersebut dimungkinkan karena sarana dan prasarana transportasi berfungsi sebagai pembentuk, pengarah, dan pemacu pertumbuhan suatu wilayah. Penyediaan sarana infrastruktur publik sangat berkaitan dengan pelayanan sosial yang akan diberikan oleh pemerintah daerah kepada masyarakat setempat.

Di era keterbukaan demokrasi pembangunan daerah tidak dapat dilepaskan dari partisipasi masyarakat. Dengan demikian pembangunan menjadi bagian tak terpisahkan dari masyarakat itu sendiri, sedangkan peran pemerintah adalah memberikan jalan atau sebagai mediator untuk mewujudkan keinginan masyarakat atas apa yang dikehendaki untuk kemajuan masyarakat di daerah. Pada hakekatnya pembangunan itu dilaksanakan oleh pemerintah bersama rakyat dengan tujuan memberikan kemakmuran dan kesejahteraan pada rakyat. Pembangunan sendiri bertujuan untuk meningkatkan kesejahteraan masyarakat. Peran pemerintah sebagai mobilisator pembangunan sangat strategis dalam 
mendukung peningkatan kesejahteraan masyarakat serta pertumbuhan ekonomi negaranya.

Salah satu pembangunan insfrastruktur yang memerlukan lahan atau tanah sangat luas adalah pembangunan jalan tol. Sebab jalan tol didesain khusus sebagai jalan alternatif jalur darat yang bebas dari hambatan. Peraturan Pemerintah Nomor 15 tahun 2005 Tentang Jalan Tol pada Pasal 1 ayat (2) menjelaskan bahwa jalan tol adalah jalanan umum yang merupakan bagian sistem jaringan jalan dan sebagai jalan nasional yang penggunaannya diwajibkan membayar tol. Dengan adanya pembangunan jalan tol ini bertujuan untuk meningkatkan aksesibilitas dan kapasitas jaringan jalan dalam melayani lalu lintas.Pembangunan jalan tol tidak lepas dari aspek fisik dan aspek non fisik pada masyarakat. Aspek fisik berkaitan dengan lingkungan sedangkan aspek non fisik adalah masalah sosial masyarakat.Kedua aspek tersebut tentunya dirasakan secara langsung oleh masyarakat yang terkena dampak dari adanya pembangunan jalan tol tersebut.

Penelitian yang dilakukan oleh Fathurosy (2018) menghasilkan adanya empat dinamika respon masyarakat atas pembangunan jalan tol, yakni dinamika yang berkaitan dengan aspek perubahan pola pikir masyarakat, aspek dinamika sosial yang berkaitan dengan interaksi masyarakat, aspek ekonomi terutama berkaitan dengan mata pencaharian atau usaha masyarakat, dan aspek yang berkaitan dengan dampak atau manfaat baik yang bersifat positif maupun negatif. Sementara penelitian yang dilakukan oleh Egi (2018) menghasilkan adanya dampak positif dan dampak negatif pembangunan jalan tol. Dampak positifnya adalah: peluang kerja terbuka bagi masyarakat sekitar, distribusi barang dan jasa lebih lancar, dan munculnya usaha-usaha yang dilakukan masyarakat sebagai efek multiplier pembangunan jalan tol seperti banyaknya masyarakat berjualan di rest area yang ada, interaksi sosial masyarakat menjadi lebih baik. Sementara dampak negatifnya berupa : banyak petani kehilangan pekerjaan karena alih fungsi lahan, dan keterpaksaan masyarakat menjadi pekerja kasar (buruh bangunan jakan).
Penelitian Victorianus (2019) menyatakan bahwa pembangunan jalan tol berdampak pada penurunan usaha batik di Pekalongan (tidak berfokus pada grosir batik, namun mencakup usaha batik di beberapa area kota Pekalongan, sedangkan faktor sosial dan lingkungan memberikan dampak positif bagi usaha batik Pekalongan.

Rencana semula pembangunan jalan tol trans Jawa tidak melewati wilayah Kota Pekalongan dan exit tol yang dibangun adalah wilayah Kabupaten Batang. Pemerintah Kota Pekalongan berupaya agar operasionalisasi jalan tol trans Jawa tidak menutup akses wilayah Kota Pekalongan, bahkan diharapkan dapat memberi dampak berupa peningkatan aksesibilitas wilayah Kota Pekalongan dan hal tersebut menjadi urgensi pembangunan exit tol di wilayah Kota Pekalongan.

Kota Pekalongan memiliki akses pintu keluar (exit) tol di wilayah perbatasan antara Kota Pekalongan dengan Kabupaten Batang, dimana exit tol tersebut langsung terakses ke pasar grosir Batik Setono. Para pengguna tol yang keluar pintu Kota Pekalongan akan langsung bisa melihat lokasi pasar grosir tersebut, yang merupakan pasar grosir batik terbesar yang ada di Kota Pekalongan. Ruas jalan tol trans Jawa menghubungkan kota-kota di sepanjang pantai utara (pantura) Jawa, membujur dari Merak sampai Banyuwangi dengan panjang keseluruhan adalah $1.167 \mathrm{Km}$. pembangunan Tol Pemalang-Batang sepanjang 39,2 kilometer menelan investasi Rp 7,5 triliun. Tol ini terdiri atas dua seksi, yakni Seksi 1 SS Pemalang-SS Pekalongan sepanjang 17,9 kilometer dan Seksi 2 SS Pekalongan-Batang sepanjang 15,9 kilometer.

Salah satu harapan dari Pemerintah Kota Pekalongan dengan dibangunnya exit tol dapat membantu kemudahan akses menuju pasar Grosir Setono, sehingga pedagang batik dari luar kota yang mau belanja ke Pekalongan lebih cepat dan mudah. Akan tetapi fenomena yang berkembang pada pedagang batik yang ada di pasar grosir Setono menyebutkan bahwa dengan dibangunnya jalan tol menyebabkan omset penjualan mereka mengalami penurunan yang cukup banyak. Kelangsungan bisnis mereka saat ini banyak terbantu dengan sistem 
penjualan secara daring (online) dan tengkulak dari luar kota yang sudah menjadi pelanggan tetapnya. Sementara itu banyak masyarakat yang tadinya memiliki mata pencaharian di bidang pertanian harus merelakan lahannya terkena dampak pembangunan jalan tol. Meskipun mereka memperoleh ganti rugi yang cukup, namun untuk beralih profesi mencari pekerjaan baru tidak mudah mengingat kebanyakan petani tidak memiliki keahlian yang lain. Di sisi lain, banyak masyarakat yang diuntungkan dengan adanya jalan tol, diantaranya adalah kesempatan memperoleh pekerjaan selama musim pembangunan jalan tol, maupun mereka yang bisa berusaha di areal rest area.

Melihat fenomena adanya persepsi masyarakat terkait kemungkinan dampak positif dan negatif atas pembangunan jalan dan exit tol baik bagi pemerintah maupun masyarakat Kota Pekalongan serta hasil penelitian terdahulu (state of the art) sebagaimana dijelaskan di muka, maka perlu dikaji secara lebih mendalam dan rinci mengenai dampak sosial ekonomi atas pembangunan jalan dan exit tol yang melewati Kota Pekalongan.

\section{BAHAN DAN METODA}

\subsection{Lingkup Penelitian}

Ruang lingkup kajian tentang Dampak Sosial-Ekonomi Pembangunan Jalan dan Exit Tol di Wilayah Kota Pekalongan meliputi seluruh masyarakat Kota Pekalongan yang terdiri atas masyarakat yang lahannya terkena dampak, masyarakat yang mata pencahariannya atau usahanya terkena dampak, para pemangku kepentingan, akademisi dan tokoh masyarakat, dan masyarakat yang memperoleh efek multiplier, dan masyarakat umum.

\subsection{Populasi dan Sampel}

Populasi penelitian adalah seluruh penduduk dewasa di Kota Pekalongan (usia 17 tahun ke atas) yang bisa diajak wawancara dan bisa mengambil keputusan. Sampel diambil dengan teknik Snowball untuk keperluan pengembangan data yang diperlukan, dengan memfokuskan pada masyarakat yang terkena dampak secara langsung serta masyarakat yang menerima efek multiplier.

\subsection{Metode Pengumpulan Data}

Data yang diperlukan dalam "Kajian Dampak Sosial Ekonomi Pembangunan Jalan dan Exit Tol di Kota Pekalongan" meliputi data sekunder dan data primer. Data sekunder seperti dokumen-dokumen kebijakan, kondisi geografis dan demografis, kondisi perekonomian, dan sebagainya dikumpulkan dengan metode dokumentasi. Sedangkan data primer yang berupa persepsi jawaban responden dikumpulkan dengan penyebaran kuesioner.

\subsection{Teknik Analisis}

Pengolahan data dilakukan dengan metode deskriptif, yang tujuannya untuk menyajikan gambaran lengkap mengenai setting sosial atau dimaksudkan untuk eksplorasi dan klarifikasi mengenai suatu fenomena atau kenyataan sosial, dengan jalan mendeskripsikan sejumlah variabel yang berkenaan dengan masalah dan unit yang diteliti antara fenomena yang diuji. Penelitian deskriptif akan menghasilkan gambaran akurat tentang sebuah kelompok, menggambarkan mekanisme sebuah proses atau hubungan, memberikan gambaran lengkap baik dalam bentuk verbal atau numerikal, menyajikan informasi dasar akan suatu hubungan, menciptakan seperangkat kategori dan mengklasifikasikan subjek penelitian, menjelaskan seperangkat tahapan atau proses, serta untuk menyimpan informasi bersifat kontradiktif mengenai subjek penelitian.

\section{HASIL}

\subsection{Responden Penelitian}

Data-data yang diperoleh berasal dari penyebaran instrument penelitian (daftar pertanyaan) yang diberikan kepada responden. Jumlah responden yang berhasil dimintai data adalah 40 orang. Dalam hal pencarian responden ini peneliti kesulitan untuk melacak masyarakat yang terkena dampak (tergusur), karena mereka kebanyakan sudah pindah ke daerah lain dan peneliti tidak memperoleh informasi alamat mereka yang baru. Dengan teknik Snowball, informasi yang diperoleh dari 40 orang responden sudah cukup untuk diolah lebih lanjut.

Responden sebanyak 40 orang tersebut terdiri atas pedagang di dalam pasar grosir Setono dan disekitar lokasi exit tol sebanyak 27 
orang, masyarakat yang lahannya tergusur 5 orang, dan pedagang baru yang memperoleh efek multiplier sebanyak 8 orang.

\subsection{Hasil Jawaban Masyarakat terhadap Pertanyaan Tertutup}

Berikut ini adalah hasil jawaban dari ke 40 responden atas pertanyaan tertutup yang diajukan:

1) Penilaian masyarakat bahwa dengan adanya pembangunan jalan dan exit tol terdapat jalur alternatif yang dapat digunakan, sebanyak 28 orang $(70 \%)$ menyatakan setuju dan sangat setuju

2) Penilaian masyarakat bahwa pembangunan jalan dan exit tol di Kota Pekalongan penting bagi masyarakat, 32 orang $(80 \%)$ menyatakan setuju dan sangat setuju

3) Penilaian masyarakat terhadap pembangunan jalan dan exit tol di Kota Pekalongan memudahkan akses bagi masyarakat, sebanyak 37 orang $(92,5 \%)$ menyatakan setuju dan sangat setuju

4) Terhadap pertanyaan bahwa dengan adanya jalan dan exit tol di Kota Pekalongan, transportasi menjadi semakin mudah dan efisien, sebanyak 37 orang $(92,5 \%)$ menyatakan setuju dan sangat setuju

5) Terhadap pertanyaan bahwa dengan adanya jalan dan exit tol di Kota Pekalongan, biaya hidup meningkat, sebanyak 21 orang $(52,5 \%)$ menyatakan setuju dan sangat setuju

6) Penilaian masyarakat terhadap pertanyaan bahwa dengan adanya jalan dan exit tol di Kota Pekalongan, akses terhadap layanan kesehatan lebih mudah, sebanyak 30 orang $(75 \%)$ menyatakan setuju dan sangat setuju

7) Penilaian masyarakat terhadap pertanyaan bahwa dengan adanya jalan dan exit tol di Kota Pekalongan, akses terhadap layanan pendidikan lebih mudah, sebanyak 28 Orang $(70 \%)$ menyatakan setuju dan sangat setuju

8) Penilaian masyarakat terhadap pertanyaan bahwa dengan adanya jalan dan exit tol di Kota Pekalongan, akses terhadap layanan pusat pemerintahan (Kelurahan, Kecamatan, Dinas/SKPD terkait) lebih mudah, hanya 6 orang $(15 \%)$ yang menyatakan setuju.

Berikut ini adalah ringkasan hasil di atas yang ditampilkan dalam bentuk grafik:

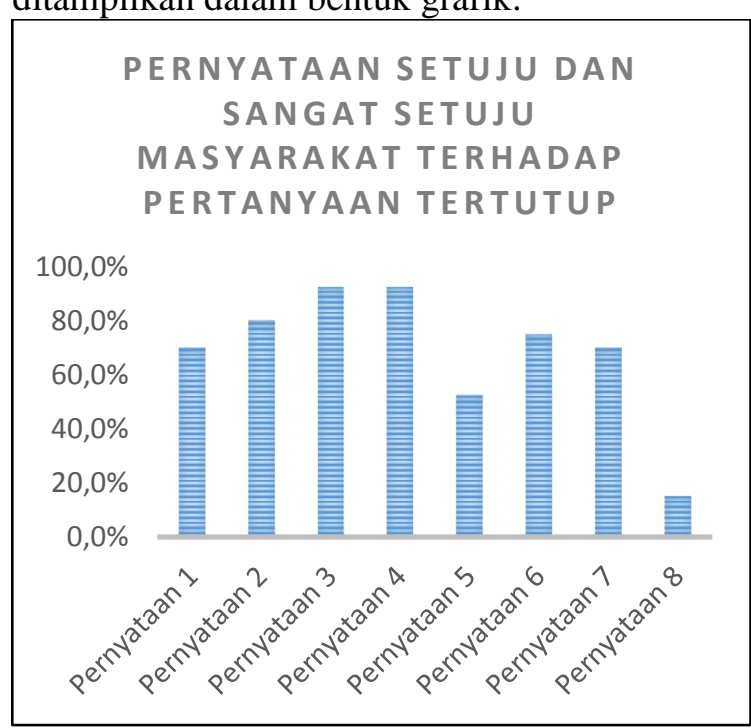

Gambar 1. Pernyataan Masyarakat

Keterangan:

Tabel 1. Keterangan Pernyataan

\begin{tabular}{|c|c|}
\hline No & Keterangan \\
\hline $\begin{array}{c}\text { Pernyataan } \\
1\end{array}$ & $\begin{array}{l}\text { Pernyataan setuju dan sangat } \\
\text { setuju masyarakat bahwa } \\
\text { dengan adanya pembangunan } \\
\text { jalan dan exit tol terdapat jalur } \\
\text { alternatif yang dapat } \\
\text { digunakan }\end{array}$ \\
\hline $\begin{array}{c}\text { Pernyataan } \\
2\end{array}$ & $\begin{array}{l}\text { Pernyataan setuju dan sangat } \\
\text { setuju masyarakat bahwa } \\
\text { pembangunan jalan dan exit tol } \\
\text { di Kota Pekalongan penting } \\
\text { bagi masyarakat }\end{array}$ \\
\hline $\begin{array}{c}\text { Pernyataan } \\
3\end{array}$ & $\begin{array}{l}\text { Pernyataan setuju dan sangat } \\
\text { setuju masyarakat terhadap } \\
\text { pembangunan jalan dan exit tol } \\
\text { di Kota Pekalongan } \\
\text { memudahkan akses bagi } \\
\text { masyarakat }\end{array}$ \\
\hline $\begin{array}{c}\text { Pernyataan } \\
\quad 4\end{array}$ & $\begin{array}{l}\text { Pernyataan setuju dan sangat } \\
\text { setuju bahwa dengan adanya } \\
\text { jalan dan exit tol di Kota } \\
\text { Pekalongan, } \\
\text { menjadi semakin mudah dan } \\
\text { efisien }\end{array}$ \\
\hline $\begin{array}{l}\text { Pernyataan } \\
5\end{array}$ & $\begin{array}{l}\text { Pernyataan setuju dan sangat } \\
\text { setuju bahwa dengan adanya }\end{array}$ \\
\hline
\end{tabular}




\begin{tabular}{|c|c|}
\hline No & Keterangan \\
\hline & $\begin{array}{l}\text { jalan dan exit tol di Kota } \\
\text { Pekalongan, biaya hidup } \\
\text { meningkat }\end{array}$ \\
\hline $\begin{array}{c}\text { Pernyataan } \\
6\end{array}$ & $\begin{array}{l}\text { Pernyataan setuju dan sangat } \\
\text { setuju masyarakat terhadap } \\
\text { pertanyaan bahwa dengan } \\
\text { adanya jalan dan exit tol di } \\
\text { Kota Pekalongan, akses } \\
\text { terhadap layanan kesehatan } \\
\text { lebih mudah }\end{array}$ \\
\hline $\begin{array}{c}\text { Pernyataan } \\
7\end{array}$ & $\begin{array}{l}\text { Pernyataan setuju dan sangat } \\
\text { setuju masyarakat terhadap } \\
\text { pertanyaan bahwa dengan } \\
\text { adanya jalan dan exit tol di } \\
\text { Kota Pekalongan, akses } \\
\text { terhadap layanan pendidikan } \\
\text { lebih mudah }\end{array}$ \\
\hline $\begin{array}{c}\text { Pernyataan } \\
8\end{array}$ & $\begin{array}{l}\text { Pernyataan setuju dan sangat } \\
\text { setuju masyarakat terhadap } \\
\text { pertanyaan bahwa dengan } \\
\text { adanya jalan dan exit tol di } \\
\text { Kota Pekalongan, akses } \\
\text { terhadap layanan pusat } \\
\text { pemerintahan (Kelurahan, } \\
\text { Kecamatan, Dinas/SKPD } \\
\text { terkait) lebih mudah }\end{array}$ \\
\hline
\end{tabular}

\subsection{Hasil Jawaban Masyarakat terhadap Pertanyaan Terbuka}

Pertanyaan terbuka yang diberikan kepada responden terkait pembangunan jalan dan exit tol meliputi : 1) apakah ada perubahan pekerjaan; 2) apakah ada perubahan omset usaha; 3) apakah akses usaha menjadi lebih mudah; 4) apakah keuntungan pembangunan jalan dan exit tol; 5) apakah kerugian pembangunan jalan dan exit tol; dan 6) apakah pembangunan jalan dan exit tol memunculkan peluang usaha. Pertanyaan terbuka ini terutama ditujukan kepada para pedagang baik yang berjualan di dalam pasar grosir Setono maupun pedagang-pedagang yang ada di sekitar exit tol dan sepanjang tepi jalan menuju exit tol.

Dari sebanyak 27 pedagang yang terjaring sebagai responden penelitian, jawabannya bisa dijelaskan sebagai berikut :

1) Dari aspek usaha yang dilakukan, seluruh pedagang (100\%) jenis usahanya tidak mengalami perubahan
2) Dilihat dari aspek pendapatan usaha, sebanyak 15 orang $(55,56 \%)$ menyatakan bahwa setelah ada jalan dan exit tol pendapatannya meningkat, 4 orang $(14,81 \%)$ menyatakan pendapatannya tetap tidak berubah, dan 8 orang $(29,63 \%)$ menyatakan pendapatannya menurun.

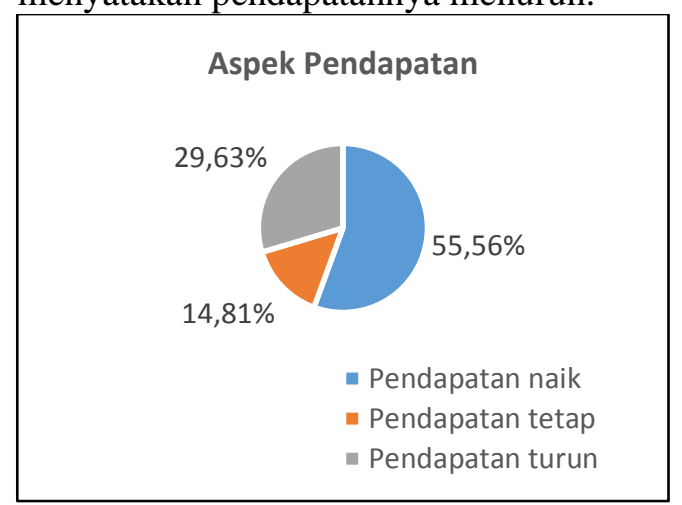

Gambar 2. Aspek Pendapatan

3) Terhadap kemudahan distribusi dan akses usaha setelah pembangunan jalan dan exit tol, 15 orang $(55,56 \%)$ dan sisanya 12 orang $(44,44 \%)$ tidak memberikan pendapat.

4) Dari sebanyak 27 pedagang, sebanyak 10 orang $(37 \%)$ menyatakan bahwa pembangunan jalan dan exit tol memberikan peluang usaha berupa penambahan kios atau toko untuk berjualan

Kemudian untuk pertanyaan terbuka tentang keuntungan dan kerugian yang timbul setelah adanya pembangunan jalan dan exit tol ditanyakan kepada seluruh responden, baik itu pedagang lama, pedagang baru yang menerima efek multiplier, maupun masyarakat yang lahannya tergusur. Dari ke 40 responden tersebut memberikan pendapat yang dapat dijelaskan sebagai berikut :

1) Beberapa keuntungan dari adanya pembangunan jalan dan exit tol adalah : mempermudah akses konsumen atau pengunjung pasar grosir dan tempat berjualan sehingga memberikan dampak pada kenaikan pendapatan usaha; harga jual tanah di sekitar jalan dan exit tol meningkat drastis; pasar grosir makin ramai 
2) Sedangkan kerugian dari adanya pembangunan jalan dan exit tol diantaranya adalah :kalau hujan air masuk ke toko (banjir) karena jalan lebih tinggi sehingga menyebabkan penjualan menurun; khusus untuk pedagang kuliner dan pusat oleh-oleh karena lokasinya di pasar ada di belakang maka pengunjungnya sepi; biaya hidup lebih mahal karena transport sehari-hari harus memutar.

\subsection{Saran / Masukan kepada Pemerintah} Kota Pekalongan

Berbagai masukan/saran dari responden yang berhasil dijaring dapat dirangkum secara komprehensif sebagai berikut :

1) Para pedagang (terutama yang berjualan di dalam pasar grosir) menghendaki agar Pemerintah Kota Pekalongan sering mengadakan even-even seperti pameran agar lebih ramai pengunjung yang diharapkan berimbas pada belanja

2) Jalan masuk pasar dan gang-gang yang menghubungkan bagian depan dan bagian belakang pasar agar di aspal atau di-paving sehingga tidak berdebu

3) Grosir agar dibuka 24 jam dan ada fasilitas full musik

4) Dibuatkan taman, dan dipasang lampulampu hias

5) Drainase agar diperbaiki

6) Iuran per kios yang dulu diadakan agar dilanjutkan lagi

7) Tempat parkir dibagi dua (depan dan belakang), sehingga pengunjung tidak hanya fokus di depan saja tapi juga di bagian belakang

8) Dibangun tempat foto (photo booth)

9) Rambu petunjuk ke arah jalan tol ditambah

10) Segera direalisasi rest area di wilayah Kota Pekalongan

\section{PEMBAHASAN}

Mencermati hasil penelitian yang sudah dijelaskan dimuka, ada beberapa hal yang bisa dibahas lebih lanjut, yaitu :

1) Lebih dari $50 \%$ responden sepakat dengan pertanyaan tertutup No. 1 s/d 7, kecuali pertanyaan No. 8. Hal ini menunjukkan bahwa secara umum masyarakat setuju (dan sangat setuju) terhadap manfaat adanya jalan dan exit tol dari aspek jalan tol sebagai jalur alternatif, jalan tol penting bagi masyarakat, memudahkan akses transportasi, meningkatkan biaya hidup, aksus ke layanan kesehatan lebih mudah, dan akses ke layanan pendidikan lebih mudah. Sedangkan terhadap layanan ke pusat-pusat pemerintahan hanya $15 \%$ responden menyatakan persetujuannya, dan lebih banyak tidak menyatakan pendapat $(75 \%)$. Jadi bisa disimpulkan bahwa adanya pembangunan jalan dan exit tol tidak mempengaruhi akses layanan ke pusat pemerintahan yang selama ini dilakukan oleh masyarakat.

2) Hasil penelitian yang berkaitan dengan jawaban atas pertanyaan terbuka yang lebih dikhususkan kepada para pedagang bisa dijelaskan sebagai berikut :

- Isu yang selama ini beredar bahwa dengan dibangunnya jalan dan exit tol menyebabkan pendapatan pedagang turun (terutama pedagang yang berjualan di pasar grosir Setono) ternyata tidak terbukti. Hal ini ditunjukkan oleh jawaban responden yang sebagian besar $(55,56 \%)$ menyatakan bahwa setelah ada jalan dan exit tol pendapatannya meningkat, dan $14,81 \%$ menyatakan pendapatannya tetep tidak berubah. Hanya ada 29,63\% responden yang menyatakan pendapatannya menurun. Responden yang menyatakan pendapatannya turun adalah mereka yang berjualan kuliner dan pusat oleholeh, karena letak jualan mereka ada di bagian belakang sehingga sepi pengunjung. Pengunjung sebagian besar memilih berbelanja di bagian depan pasar yang berdekatan dengan lokasi parkir kendaraan pengunjung.

- Isu terhadap sepinya usaha yang dilakukan oleh para pedagang dengan sendirinya juga terbantah dari hasil penelitian ini. Selain sebagian besar pedagang menyatakan pendapatannya meningkat setelah dibangunnya jalan dan exit tol, hal ini juga didukung oleh 
fakta bahwa sebanyak $37 \%$ pedagang menyatakan akan menambah toko atau kios untuk berjualan. Dengan demikian dapat disimpulkan bahwa dengan dibangunnya jalan dan exit tol justru menyebabkan perdagangan semakin ramai. Hal ini juga didukung oleh bermunculannya pedagangpedagang baru disekitar exit tol sebagai bagian dari efek multiplier atas pembangunan jalan dan exit tol di wilayah Kota Pekalongan.

3) Mencermati berbagai masukan yang diberikan oleh responden sebagaimana diuraikan di atas, Pemerintah Kota melalui SKP terkait diharapkan dapat berkoordinasi dengan pengelola pasar grosir untuk menindaklanjuti saran/masukan yang sekiranya bisa segera direalisasikan. Hal ini dimaksudkan agar wilayah di pasar dan sekitar exit tol menjadi tertata rapi sehingga para pedagang maupun pengunjung (pembeli) yang datang merasa nyaman dalam bertransaksi.

\section{PENUTUP}

\subsection{Simpulan}

Simpulan terkait hasil penelitian tentang "Dampak Sosial Ekonomi Pembangunan jalan dan Exit Tol di Wilayah Kota Pekalongan" secara umum dapat diuraikan sebagai berikut :

1) Rencana semula pembangunan jalan tol trans Jawa tidak melewati wilayah Kota Pekalongan dan exit tol yang dibangun adalah wilayah Kabupaten Batang. Pemerintah Kota Pekalongan berupaya agar operasionalisasi jalan tol trans Jawa tidak menutup akses wilayah Kota Pekalongan, bahkan diharapkan dapat memberi dampak berupa peningkatan aksesibilitas wilayah Kota Pekalongan dan hal tersebut menjadi urgensi pembangunan exit tol di wilayah Kota Pekalongan.

2) Secara umum masyarakat menyatakan bahwa pembangunan jalan dan exit tol memudahkan akses transportasi ke layanan kesehatan dan layanan pendidikan, namun tidak mempengaruhi kemudahan akses transportasi ke layanan pemerintahan.
3) Hasil penelitian ini juga menepis isu yang selama ini beredar bahwa dengan dibangunnya jalan dan exit tol menyebabkan pendapatan pedagang turun (terutama pedagang yang berjualan di pasar grosir Setono). Hal ini ditunjukkan oleh jawaban responden yang sebagian besar $(55,56 \%)$ menyatakan bahwa setelah ada jalan dan exit tol justru pendapatannya meningkat, dan beberapa pedagang menyatakan ada dampak positif yaitu akan menambah kios atau toko untuk berjualan.

4) Beberapa saran yang disampaikan oleh masyarakat adalah : 1) Pemerintah Kota Pekalongan sering mengadakan even-even seperti pameran agar lebih ramai pengunjung yang diharapkan berimbas pada belanja, 2) Jalan masuk pasar dan gang-gang yang menghubungkan bagian depan dan bagian belakang pasar agar di aspal atau di-paving sehingga tidak berdebu, 3) Grosir agar dibuka 24 jam dan ada fasilitas full musik, 4) Dibuatkan taman, dan dipasang lampu-lampu hias, 5) Drainase agar diperbaiki, 6) Iuran per kios yang dulu diadakan agar dilanjutkan lagi, 7) Tempat parkir dibagi dua (depan dan belakang), sehingga pengunjung tidak hanya fokus di depan saja tapi juga di bagian belakang, 8) Dibangun tempat foto (foto boot) di area pasar, 9) Rambu petunjuk ke arah jalan tol ditambah, dan 10) Segera direalisasi rest area di wilayah Kota Pekalongan

\subsection{Rekomendasi}

Berdasarkan uraian di atas, tim pengkaji menyampaikan rekomendasi yang dapat ditindaklanjuti, yaitu :

1) Pemerintah Kota Pekalongan melalui SKPD terkait diharapkan dapat berkoordinasi dengan pengelola pasar grosir Setono untuk menindaklanjuti saran/ masukan yang sekiranya bisa segera direalisasikan. Hal ini dimaksudkan agar wilayah di pasar dan sekitar exit tol menjadi tertata rapi sehingga para pedagang maupun pengunjung (pembeli) yang datang merasa nyaman dalam bertransaksi. 
2) Mencermati tanggapan responden pada pertanyaan mengenai adanya jalan dan exit tol di Kota Pekalongan terhadap akses layanan pusat pemerintahan (Kelurahan, Kecamatan, Dinas/SKPD terkait) yang menyatakan setuju hanya $15 \%$ responden dan sebagian besar tidak berpendapat dan lainnya menyatakan tidak setuju.Ini artinya bahwa keberadaan Exit Tol belum memberikan kemudahan bagi sebagian masyarakat terdampak untuk mendapatkan layanan pemerintahan secara cepat karena untuk mencapai ke layanan pemerintahan, masyarakat harus melewati rute yang harus memutar oleh karena itu Pemerintah perlu mempertimbangkan relokasi tempat pelayanan yang terdampak atau pembuatan jalan alternatif.

\section{DAFTAR PUSTAKA}

Ase Satria, 2017. Teori Pembangunan : Definisi Pembangunan Masyarakat serta Tujuan Pembangunan yang Dilakukan Dalam Proses Pembangunan. www.materibelajar.id

Egi Loveyan Jaya. (2018). Dampak Pembangunan Jalan Tol Bakauheni Terbanggi Besar

Fathurosy Yustisiawan Nur Imami, 2018. Dinamika Masyarakat Desa Bangkak Kec. Banyudono Kabupaten Boyolali terhadap Pembangunan Jalan Tol ruas Solo-Boyolali, UIN Sunan Kalijaga Yogyakarta

Irfantri mahaputra, 2018. “Analisis Dampak Pembangunan Jalan Tol Trans Sumatra terhadap Sosial Ekonomi Masyarakat (Studi Kasus Kondisi Sosial Ekonomi Masyarakat di Desa Jatimulyo, Kecamatan Jatiagung Kabupaten Lampung Selatan); UIN Raden Intan Lampung.

Kartasasmita, Ginanjar, 1997. Adminidtrasi Pembangunan : Perkembangan Pemikiran dan Praktiknya di Indonesia, LP3ES, Jakarta

Septo Indarto, 2012. Indonesia dan Pembangunan dibidang Infrastruktur. http://septosuhanda.wordpress.com
Siagian, S.P., 1994. Manajemen Modern, Bunga Rampai. CV. Masagung, Jakarta

Siti Nurhayati, 2012. Metodologi Penelitian Praktis, edisi dua. UNIKAL Press, Pekalongan

Suratmo, Gunawan F. (2002), Analisis Mengenai Dampak Lingkungan, Gadjah Mada University Press.

Tikson, Deddy, 2005. Keterbelakangan dan Ketergantungan, Teori Pembangunan di Indonesia, Malaysia, dan Thailand. Ininnawa, Makasar

Uswatun Khasahah, Nurhadji Nugraha, Wawan Kokotiasa, 2017. Dampak Pembangunan Jalan Tol Solo-Kertosono terhadap Hak EkooonnnomiMasyarakat desa Kasreman Kec. Geneng Kab. Ngawi. Citizenship Jurnal Pancasila dan Kewarganegaraan Avaliable online at : http://e-journal.unipma .ac.id/index.php/ citizenship ISSN: 2302-433X (print) 2579-5740 (online)

Victorianus Victorianus Aries Siswanto, Tri Pudji Wahjuningsih, Murtini. 2019. Dampak Pembangunan Jalan Tol Terhadap Faktor Sosial, Ekonomi dan Lingkungan pada Usaha Batik dan Perhotelan di Kota Pekalongan. Jurnal Litbang Kota Pekalongan, Volume 17 Tahun 2019

Peraturan Pemerintah Nomor 15 tahun 2005 Tentang Jalan Tol http://www.bpkp.go.id/uu/filedownload/4 $\underline{160 / 864 . b p k p}$

\begin{tabular}{|c|}
\hline 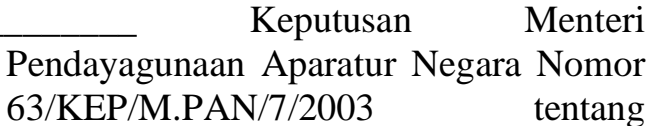 \\
\hline Pedoman Umum Penyelenggaraan \\
\hline $\begin{array}{l}\text { Pelayanan Publik } \\
\text { The Physical Quality of Life }\end{array}$ \\
\hline $\begin{array}{l}\text { Index (PQLI); } \text { http://www.wikipedia.org. } \\
\text { Ruas Jalan Tol Trans Jawa; } \\
\text { https://id. wikipedia. org /wiki } \\
\text {; Resmi, Tol Pejagan-Pemalang }\end{array}$ \\
\hline $\begin{array}{l}\text { dan Pemalang-Batang Beroperasi; } \\
\text { https://properti.kompas.com/read/2018/1 } \\
\text { 1/09/123522621/resmi-tol-pejagan- } \\
\text { pemalang-dan-pemalang-batang- } \\
\text { beroperasi }\end{array}$ \\
\hline
\end{tabular}

